\title{
Uncovering Pakistan's Environmental Risks and Remedies under the China-Pakistan Economic Corridor
}

\author{
Shahzad Kouser $^{1}$ (D) Abdul Subhan ${ }^{1} \cdot$ Abedullah $^{2}$ \\ Received: 21 August 2019 / Accepted: 17 December 2019 / Published online: 26 December 2019 \\ (C) Springer-Verlag GmbH Germany, part of Springer Nature 2019
}

\begin{abstract}
The China-Pakistan Economic Corridor (CPEC) is a journey towards economic integration of Eurasia. The CPEC contains US\$62 billion investment projects on energy, infrastructure, and other development projects in Pakistan. However, CPEC could enhance climate change vulnerabilities for the faltering economy of Pakistan due to its three possible environmental risks and repercussions. Its major environmental concern is related to energy projects as three quarters of the newly planned energy will be generated from traditional coal-fired power plants. Traditional coal power plants are the major contributors to $\mathrm{CO}_{2}$ emissions and smog, which ultimately lead to global warming and climate change. Its second important environmental concern is linked with massive tree cutting for the construction of various road networks from Kashghar, China, to Gwadar, Pakistan. Tree cutting leads to enormous concentration of $\mathrm{CO}_{2}$ emissions along the road networks. Vehicle trafficking is its third important environmental threat. Karakorum highway is expected to carry up to 7000 trucks per day that will release up to 36.5 million tons of $\mathrm{CO}_{2}$. Despite all the environmental risks, the CPEC enables Pakistan to manage energy crisis and upgrade aging infrastructure. However, if appropriate remedial measures are not taken to diminish environmental risks, Pakistan will be among major contributors to $\mathrm{CO}_{2}$ emissions, and its rank will be worsen in global climate risk index, after completion of this project. Therefore, it is very crucial to assess possible environmental impacts of CPEC projects regarding energy, infrastructure, and transportation. Furthermore, scientists from both countries should collaborate to manage the environmental repercussions of CPEC projects.
\end{abstract}

Keywords CPEC $\cdot$ Environmental risks $\cdot$ Energy $\cdot$ Infrastructure $\cdot$ China $\cdot$ Pakistan

Dear Editor,

The China-Pakistan Economic Corridor (CPEC) is a framework of regional connectivity. One Belt One Road initiative comprises of two trade connections: Silk Road Economic Belt and Maritime Silk Road for the economic integration of Eurasia. The CPEC is the part of Silk Road Economic Belt and was launched in 2015. The CPEC contains US\$62 billion projects on energy, infrastructure, and other development projects in Pakistan (CPEC 2019). It is considered a game changer for the faltering economy of Pakistan as it is predicted to accelerate country's economic growth at $7.5 \%$ during the

Responsible Editor: Eyup Dogan

Shahzad Kouser

drskouser@comsats.edu.pk

1 Department of Economics, COMSATS University Islamabad, 45550 Park Road, Islamabad, Pakistan

2 Pakistan Institute of Development Economics, Islamabad, Pakistan period of 2015-2030 (Mirza et al. 2019). It is further predicted that CPEC will create around 700,000 new jobs in Pakistan by expediting mineral exploration, agricultural development, IT revolution, communication networks, trade, and investment till 2030 (The News 2019). The CPEC is also important for China's economy as it will boost trade of Chinese products by providing the shortest route to the markets of Middle East, Africa, and Europe (Khursheed et al. 2019). Moreover, China will get the opportunity to develop its north-western territory Xinjiang.

In addition to economic benefits, the CPEC has huge potential to address climate risks and environmental problems of Pakistan. Pakistan ranks seven among top ten climate changevulnerable countries in the long-term global climate risk index 2019 (Eckstein et al. 2019). Moreover, the country is facing multidimensional challenges of climate change such as floods, droughts, heat waves, diseases, and increase in poverty and hunger (Nabi et al. 2019). In contrast to put more stringent measures on environmental factors in the implementation of development projects, Environmental Impact Assessment 
(EIA) has been ignored in the formulation of CPEC projects. Recent studies have warned that the CPEC investments shall have direct adverse impacts on Pakistan's water, air, and biodiversity (Huang et al. 2017; Zhang et al. 2017). The possible environmental concerns may drastically reduce the CPEC's potential benefits.

One of the major environmental concerns of the CPEC is related to energy projects in Pakistan. To encounter energy crisis in the country, the CPEC's major investment, US\$33 billion, is allocated to 19 energy projects, and three quarters of the newly planned energy will be generated from traditional coal-fired power plants in Sindh (Thar-I and Thar-II coal power plants), Punjab (Sahiwal and Salt Range coal power plants), and Balochistan (Hub and Gwadar coal power plants) provinces (CPEC 2019). On the fact, traditional coal power plants are the major contributors to $\mathrm{CO}_{2}$ emissions and smog, which ultimately lead to global warming and acid rain (UCSUSA 2017). Already seasonal smog has engulfed large areas of Punjab and Sindh provinces, and it has resulted in many fatal road accidents due to zero visibility and hospital admissions every year. Envision, what will happen to the environment of these provinces when coal power plants start their full operation (Ali 2018), as coal fires along with automobile exhausts and burning of agricultural wastes are three major sources of smog (Stanley 2019). Further, poor air quality in these areas will result in growing cases of asthma, lung tissue damage, bronchial infection, and heart attack. Greenhouse gas (GHG) emissions coming from coal-fired power plants can be reduced up to $33-45 \%$ by adopting ultra-supercritical coal technology that helps to convert GHGs or particulate matter into supercritical fluids before releasing to the atmosphere (Myllyvirta 2017). Besides, supercritical fluids can be used to make acids, which are used as a raw material in different industries like pharmaceutical industry (Kern 2008). The upfront cost of this technology is 20-30\% higher than traditional coal-fired power plants (Power Technology 2016), but its life span is 10-15 years more than traditional technology (Kumar et al. 2015). China has also switched to this modern technology 10 years back, after suffering from huge health burden due to polluted gray skies in six cities (Ali 2018; Yu and Abler 2010). Under the CPEC, 30\% of energy investment is targeted on renewable energy generation alternatives such as hydro, solar, and wind power projects to avoid greenhouse gas emissions in the country (CPEC 2019). However, this is high time either to redirect most of CPEC investment in renewable energy projects to abridge energy gaps as Pakistan has huge potential for these environmentally sustainable solutions or to at least switch to supercritical coal technology.

Another major environmental concern of CPEC is linked with cutting down trees on large scale for the construction of various road networks in Pakistan. The CPEC road networks can be divided into northern section and three other alignments, western, eastern, and central, which start Kashghar in the western part of China and end in Pakistan through Gwadar, Balochistan (CPEC 2019). More than 54,000 fruit or non-fruit/forest trees have been chopped down in Abbottabad, Nowshera, Lower Dir, Swabi, Mardan, and Malakand districts in 2017 (Sadaqat 2017; SDPI 2018). A tree can absorb 50 pounds of $\mathrm{CO}_{2}$ per year and can play important role to mitigate risks of climate change $\left(\mathrm{CO}_{2}\right.$ Measurement Specialists 2018). After massive cutting, 7 million pounds of $\mathrm{CO}_{2}$ were not absorbed by trees in these districts in 2017 and are still accumulating in the atmosphere. These districts are already at high risks of climate change that appears in the form of increased temperature, droughts, soil erosion, untimely rains, and glacier melting that ultimately lead to extreme flooding. Nowshera, Lower Dir, Swabi, Mardan, and Malakand are previously the most vulnerable districts to monsoon flooding (Ali 2017). Tourism industry of these districts has also badly affected. Afforestation is the only remedy to protect biodiversity and deteriorated natural environment. It is required to plant eight trees as a reparation for an uprooted one (Sadaqat 2017), besides compensating owner of the land with reasonable standing value of each tree. Current plantation drive needs to be more rigourous in terms of tree selection and monitoring.

Vehicle trafficking is also an important environmental threat under CPEC in the northern areas of Pakistan. After the completion of road networks under CPEC, the Karakorum highway is expected to carry up to 7000 trucks per day that release up to 36.5 million tons of $\mathrm{CO}_{2}$ on the way to Gwadar (Qazibash 2017). $\mathrm{CO}_{2}$ emissions and particulate matter will change the local climate by deteriorating the air quality. Air pollution has both acute and chronic health effects and contributes to increase morbidity and hospital admissions. Increased $\mathrm{CO}_{2}$ emission will drastically melt the glaciers and will increase flash floods. In Baluchistan, 2019 sudden and unexpected flood has affected 40,000 people, with the loss in property and livelihood (WHO 2019). Emissions of $\mathrm{CO}_{2}$ and particulate matter can be combated through adopting the following measures such as improving the aerodynamic character of vehicles; switching to alternative fuels e.g., biodiesel; improving road infrastructure; revising maximum weights and dimension of heavy-duty vehicles under European Molecular System (EMS), and truck platooning (linking of two or three self-driving trucks in convoy). However, EMS has maximum effect to combat $\mathrm{CO}_{2}$ emissions (EAMA 2017). These measures have been proved to be successful in all adopted countries such as Denmark, Finland, the Netherlands, and Sweden, while successful tests are underway in Belgium, Germany, and Spain (EAMA 2017). Nonetheless, catalytic converters suggested by earlier studies can change only the GHGs from unstable to stable form (Catalytic Converts 2019), despite expensive technology and short life span. Another possible remedy to reduce $\mathrm{CO}_{2}$ emissions is the employment of electric vehicles to ensure eco-friendly corridor. 
Despite all the environmental risks, the CPEC enables Pakistan to manage energy crisis and upgrade aging infrastructure. However, if appropriate remedial measures are not taken to diminish environmental risks, Pakistan will be among major contributors to $\mathrm{CO}_{2}$ emissions, and its rank will be worsen in global climate risk index, after completion of this project. Therefore, it is very crucial to assess possible environmental impacts of CPEC projects regarding energy, infrastructure, and transportation. Furthermore, scientists from both countries should collaborate to manage the environmental repercussions of CPEC projects.

\section{References}

Ali M (2017) Peshawar among districts most vulnerable to monsoon floods. DAWN. Retrieved from https://www.dawn.com/news/ 1343539

Ali M (2018) Pakistan's quest for coal-based energy under the ChinaPakistan economic corridor (CPEC): implications for the environment. Environ Sci Pollut Res 25:31935-31937

Catalytic Converters (2019) Retrieved from https://chem.libretexts.org

$\mathrm{CO} 2$ Measurement Specialists (2018) Could global $\mathrm{CO}_{2}$ levels reduced by planting trees? Retrieved from https:/www.co2meter.com/blogs/ news/could-global-co2-levels-be-reduced-by-planting-trees

CPEC (2019) CPEC and Pakistani economy: an appraisal. CPEC Center of Excellence, Islamabad

EAMA (2017) Effective measures to combat $\mathrm{CO}_{2}$ emissions. European Automobile Manufacturers Association

Eckstein D, Hutfils ML, Winges M (2019) Global climate risk index 2019: who suffers Most from extreme weather events? Weatherrelated loss events in 2017 and 1998 to 2017. Germanwatch e.V, Berlin

Huang Y, Fischer TB, Xu H (2017) The stakeholders analysis for SEA of Chinese foreign direct investment: the case of "one belt, one road" initiative in Pakistan. Impact Asses Project Apprais 35(2):158-171

Kern W (2008) Overview and evolution of silicon wafer cleaning technology

Khursheed A, Haider SK, Mustafa F, Akhtar A (2019) China-Pakistan economic corridor: a harbinger of economic prosperity and regional peace. Asian J German Eur Stud 4(1):1-15
Kumar R, Sharma A, Tewari PC (2015) Cost analysis of a coal fired power plant using the NPV method

Mirza FM, Fatima N, Ullah K (2019) Impact of China-Pakistan economic corridor on Pakistan future energy consumption and energy saving potential: evidence from Sectoral time series analysis. Energy Strateg Rev 25:35-46

Myllyvirta L (2017) How much do ultra-supercritical coal plants really reduce air pollution? Retrieved from https://energypost.eu/howmuch-do-ultra-supercritical-coal-plants-really-reduce-air-pollution/

Nabi G, Ali M, Khan S, Kumar S (2019) The crisis of water shortage and pollution in Pakistan: risk to public health, biodiversity, and ecosystem. Environ Sci Pollut Res 26:10443-10445

Power Technology (2016) Lean and clean: why modern coal-fired power plants are better by design. Retrieved from https://www. powertechnology.com/features/featurelean-and-clean-why-moderncoal-fired-power-plants-are-better-by-design-4892873/

Qazibash Z (2017) CPEC-moving from discussion to solutions. Retrieved from https://tribune.com.pk/story/1368953

Sadaqat M (2017) Cutting down trees for CPEC. Retrieved from https:// herald.dawn.com/news/1153738

SDPI (2018) Preliminary environmental impact assessment (EIA) study for China-Pakistan economic corridor (CPEC) northern route road construction activities in Khyber-Pakhtunkhwa (KPK), Pakistan. Sustainable Development Policy Institute, Islamabad

Stanley M (2019) Smog is Air Pollution that Reduce Visibility. Retrieved from https://www.nationalgeographic.org/encyclopedia/smog/

The NEWS (2019) CPEC to create 700,000 direct jobs for Pakistanis by 2030. The News. https://obortunity.org/2019/01/09/cpec-to-create700000-direct-jobs-for-pakistanis-by-2030/

UCSUSA (2017) Coal and air pollution. Union of Concerned Scientists Science for Healthy Planet and Safer World

WHO (2019) Pakistan: floods in Baluchistan. The World Health Organization, Geneva, Switzerland Retrieved from http://www. emro.who.int/pak/pakistan-infocus/floods-in-balochistan.html

Yu X, Abler D (2010) Incorporating zero and missing responses into CVM with open-ended biding: willingness to pay for blue skies in Beijing. Environ Dev Econ 15:535-556

Zhang R, Andam F, Shi G (2017) Environmental and social risk evaluation of overseas investment under the China-Pakistan economic corridor. Environ Monit Assess 189(6):253

Publisher's note Springer Nature remains neutral with regard to jurisdictional claims in published maps and institutional affiliations. 